\title{
Mathematical modeling of the main technological parameters of the two-rotor shock-centrifugal disintegrator on the basis of correlation analysis
}

\author{
Volodymyr Nadutyi ${ }^{1}$, Anastasiia Loginova ${ }^{1, *}$, and Vitalii Sukhariev ${ }^{1}$ \\ ${ }^{1}$ Institute of Geotechnical Mechanics named by N. Poljakov of National Academy of Sciences of \\ Ukraine, 49005, Dnipro, Simferopolska Str., 2a, Ukraine
}

\begin{abstract}
Technological disintegration indicators (productivity and power consumption) were determined and their generalized multiple regression variability depending on the regime and structural parameters of the shockcentrifugal disintegrator and the parameters of the output product were obtained. Economic and technological advantages of using the two-rotation kinematic scheme of a shock-centrifugal disintegrator, which implements the destruction of the material mainly by shock shifts due to the combined action of the kinetic energy of the interconnected flows, were justified. The research was carried out using such types of rocks: granite, tuff, limestone, basalt. The nature of the dependencies was determined by comparing the corresponding values of the reliability of different types of approximation.
\end{abstract}

\section{Introduction}

In $[1,2]$, it was substantiated in detail that methods and means that implement mainly shear loads are the most energy-saving approach to the destruction of materials. It is impossible to realize the destruction by shear loads using a single-rotor kinematic circuit of a shockcentrifugal disintegrator (hereinafter SCD). Such a mechanism of destruction can be realized by changing the kinematic scheme from single-rotor to two-rotor [3]. Thus, new structural elements and their interaction make it possible to form a new zone of disintegration with the combined effect of shock compression and shear loads, as a result there is a product of a wide range of sizes with a slight increase of energy costs, that improves the technological and operational characteristics of the disintegrator [4].

Two-rotor SCD design [3,5] has additional (identical to the first) acceleration rotors installed along the inner surface of the chamber of disintegration with the formation of a central gap and the possibility of rotation in one direction. The corresponding openings for loading the material are made above each of the rotors in the case cover. The boot device is multichannel and each of the channels is connected to the corresponding opening in the cover. The principle of operation of two-rotor SCD is shown on Figure 1. In the process of

\footnotetext{
*Corresponding author: An.O.Loginova@gmail.com
} 
developing a disintegrator, which uses a cumulative effect of the destruction of raw materials by the impact of shock compressive and shear loads, a patent of Ukraine was obtained (Fig. 2) [3, 5]. And also a laboratory test bench was created, which served as an experimental model of a shock-centrifugal disintegrator of two-rotor design.

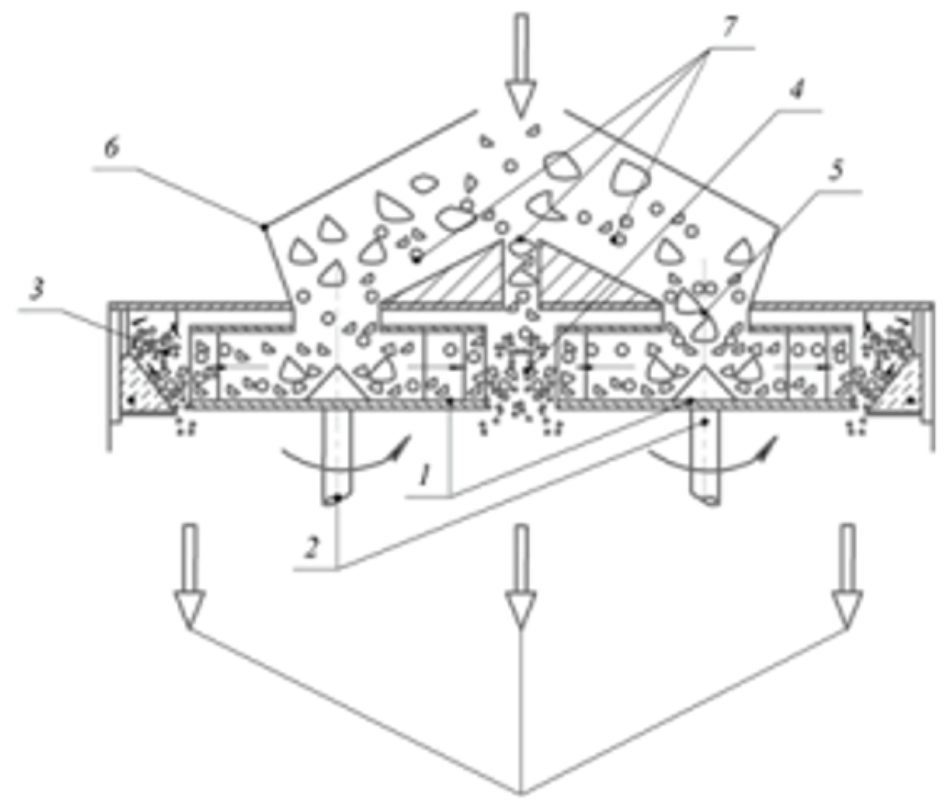

Fig. 1. Principle of operation of two-rotor SCD.

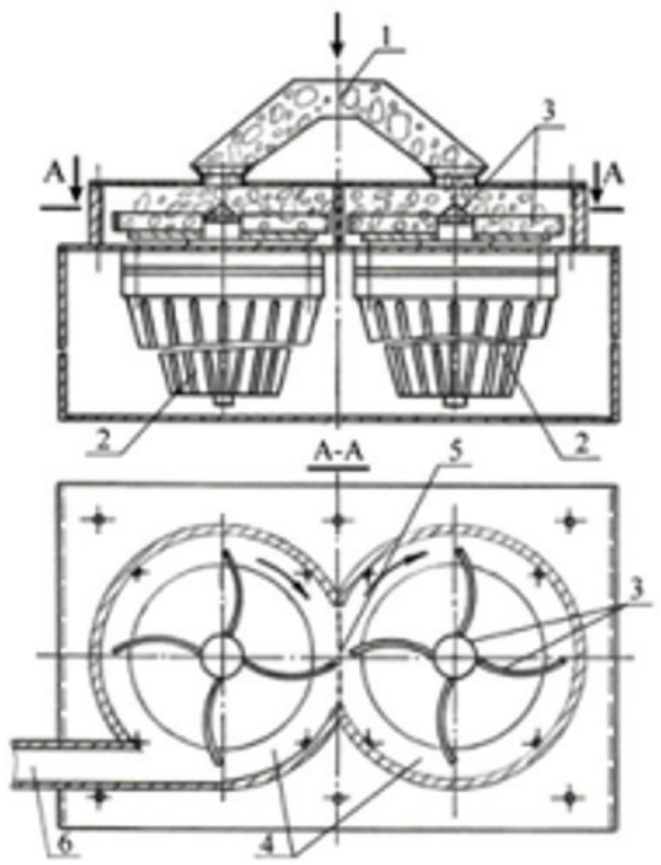

Fig. 2. Scheme of a laboratory stand of two-rotor shock-centrifugal disintegrator: 1 - boot device; 2 electric drive; 3 - acceleration rotor with shoulder blades; 4 - working chamber; 5 - central disintegration zone; 6 - unloading opening. 
The operation of proposed shock-centrifugal disintegrator is following (Fig. 1). The material for disintegration is fed into a multichannel boot device (6), where each of the channels (7) is connected to the corresponding opening in the disintegrator cover. Through these openings, the material enters the acceleration rotors (1) mounted along the inner surface of the disintegration chamber (3) on one side rotating shafts (2) and directly into the central gap (4) formed in the space between the rotors (1). So, the central zone of disintegration is formed in the gap (4), and the peripheral zone is formed on the borehole plates (3).

Due to the combined effect of kinetic energy directed to the flow of grinded material, in the central zone of disintegration a complex process of particle destruction is realized. Shear loads make it possible to obtain a product of a wide range of grain, to manage the process of disintegration, and also to reduce the output of the oversize, which causes a significant increasing the efficiency of disintegration under the same energy costs.

\section{Method of correlation analysis of technological disintegration indicators}

To justify the kinematic scheme and to determine the technological parameters of disintegration in SCD, the method of correlation analysis [6] was used. The nature of each of the dependencies is obtained by comparing the corresponding values of the reliability of different types of approximation.

As variable parameters (so-called indicated factors) were used the following:

1. Number of rotors $x_{1}-$ one or two rotors.

2. The initial size of the material $x_{2}:-10+7 \div-5+2.5 \mathrm{~mm}$.

3. Durability of the material $x_{3}: 35 \div 230 \mathrm{~kg} / \mathrm{mm}^{2}$.

4. Number of revolutions of the shaft of the disintegrator $x_{4}: 2800-4760 \mathrm{rpm}$.

\section{Results of research}

According to the results of described in detail in [4] experimental data correlation analysis, the dependences (Table 1, Fig. 3, Fig. 4), which determine the productivity $Q$ and the power $N$ spent on grinding in a shock-centrifugal disintegrator of all the indicated factors were obtained.

The evaluation of the significance of the equations using Fisher's statistics has shown that they are significant.

The average error of approximation in determining the power of SCD is $14.6 \%$, power consumption is $12.7 \%$, which indicates a satisfactory coincidence of theoretical and experimental values.

Table 1. Multiple regressive dependencies.

\begin{tabular}{|c|c|}
\hline Multiple regression dependence & $\begin{array}{c}\text { Determination } \\
\text { coefficient }\end{array}$ \\
\hline$Q=188.3 x_{1} x_{2}^{-0.75} x_{3}^{-0.6} x_{4}^{0.31}$ & 0.92 \\
\hline$N=10^{-4} x_{1}^{0.15} x_{2}^{0.7} x_{3}^{0.24} x_{4}^{1.37}$ & 0.96 \\
\hline
\end{tabular}




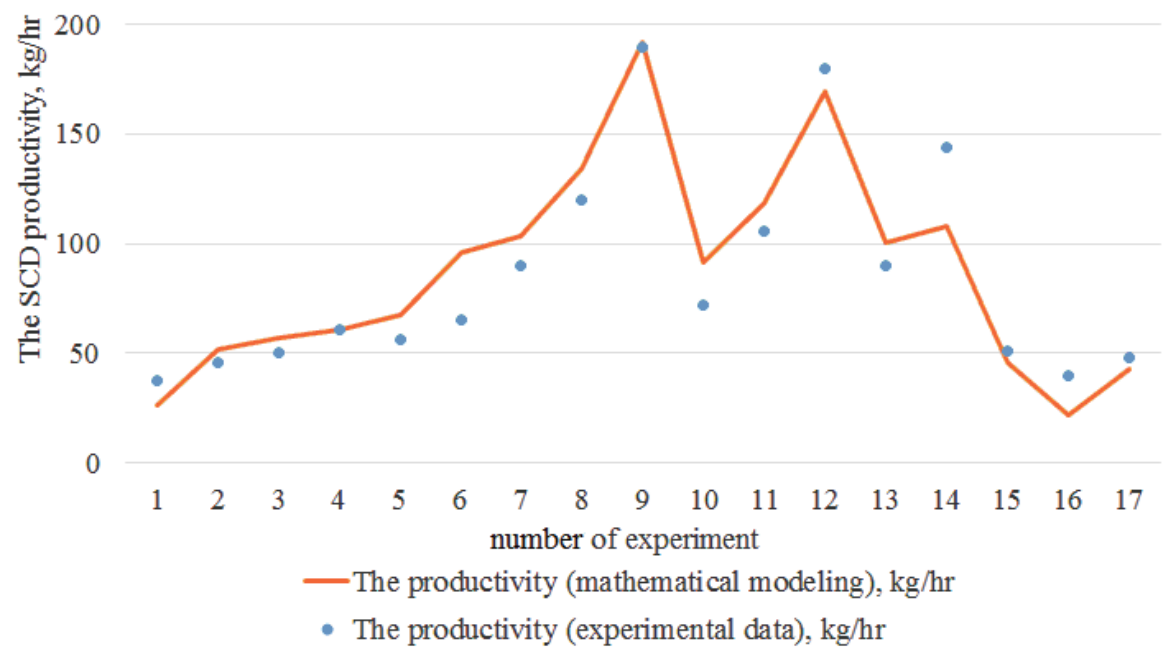

Fig. 3. Graph of multiple 4-factor regression equation for determining SCD productivity.

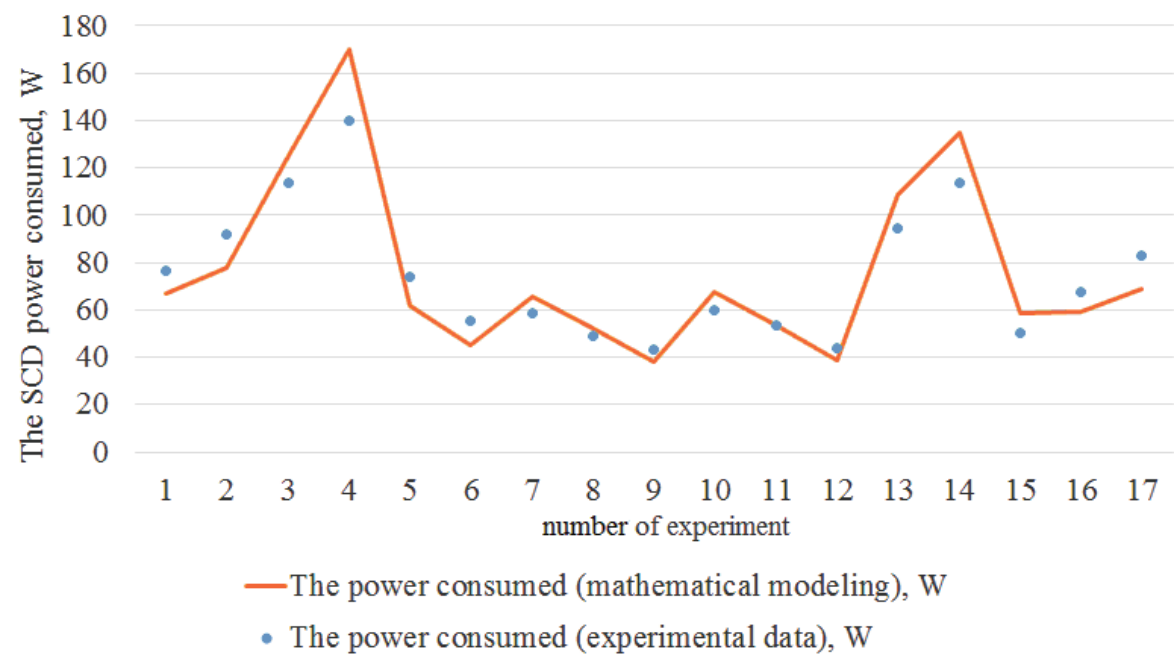

Fig. 4. Graph of multiple 4-factor equation of regression to determine the power consumed on disintegration of raw materials in SCD.

The productivity and power consumption of SCDs have a multiple regression dependingence from the number of rotors, the speed of the shaft, the size and strength of the source material. Two-rotation kinematic CD scheme, which implements the destruction of the material mainly by shear loads, compared to single-rotor, increases productivity of disintegration in 2 times with an increase in power consumption - $15 \%$.

To determine intermediate regression equations with several indicated factors in the multiple regression equation (Table 1), instead of unclaimed factor characteristics it is necessary to put their mean values equal to: $\bar{x}_{1}=2 ; \bar{x}_{2}=7 ; \bar{x}_{3}=87 ; \bar{x}_{4}=3146$.

The corresponding factors for the pure regression equation are presented below (Table 2 and Table 4). 
Table 2. The pure regression equations for determining the productivity of SCD.

\begin{tabular}{|c|c|}
\hline A pure regression equation & Approximation accuracy \\
\hline$Q\left(x_{1}\right)=36.4 x_{1}$ & $\varepsilon=8 \%$ \\
\hline$Q\left(x_{2}\right)=283.1 x_{2}^{-0.75}$ & $\varepsilon=14.9 \%$ \\
\hline$Q\left(x_{3}\right)=972.5 x_{3}^{-0.6}$ & $\varepsilon=6.8 \%$ \\
\hline$Q\left(x_{4}\right)=5.36 x_{4}^{0.31}$ & $\varepsilon=14.9 \%$ \\
\hline
\end{tabular}

The pair coefficients of correlation of investigated indicated factors and productivity $y$ of SCD are given in Table 3.

Table 3. The pair coefficients of correlation of investigated indicated factors and productivity $y$ of SCD.

\begin{tabular}{|c|c|c|c|c|}
\hline$r_{x 1 y}$ & $r_{x_{2} y}$ & $r_{x_{3} y}$ & $r_{x_{4} y}$ & $r_{x_{1} x_{2}}$ \\
\hline 0.52 & -0.46 & -0.77 & 0.12 & -0.20 \\
\hline$r_{x_{1} x_{3}}$ & $r_{x_{1} x_{4}}$ & $r_{x_{2} x_{3}}$ & $r_{x_{2} x_{4}}$ & $r_{x_{3} x_{4}}$ \\
\hline-0.28 & 0.24 & 0.01 & 0.43 & -0.02 \\
\hline
\end{tabular}

Table 4. The pure regression equations for determining the power consumption of SCD.

\begin{tabular}{|c|c|}
\hline A pure regression equation & Approximation accuracy \\
\hline$N\left(x_{1}\right)=71.16 x_{1}^{0.15}$ & $\varepsilon=12.9 \%$ \\
\hline$N\left(x_{2}\right)=20.25 x_{2}^{0.7}$ & $\varepsilon=6.3 \%$ \\
\hline$N\left(x_{3}\right)=26.92 x_{3}^{0.24}$ & $\varepsilon=14.9 \%$ \\
\hline$N\left(x_{4}\right)=0.001 x_{4}^{1.37}$ & $\varepsilon=14.8 \%$ \\
\hline
\end{tabular}

The pair coefficients of correlation of investigated indicated factors and productivity $y$ of SCD are given in Table 5.

Table 5. The pair coefficients of correlation of investigated indicated factors and productivity $y$ of SCD.

\begin{tabular}{|c|c|c|c|c|}
\hline$r_{x 1 y}$ & $r_{x_{2} y}$ & $r_{x_{3} y}$ & $r_{x_{4} y}$ & $r_{x_{1} x_{2}}$ \\
\hline 0.16 & 0.61 & 0.29 & 0.83 & -0.20 \\
\hline$r_{x_{1} x_{3}}$ & $r_{x_{1} x_{4}}$ & $r_{x_{2} x_{3}}$ & $r_{x_{2} x_{4}}$ & $r_{x_{3} x_{4}}$ \\
\hline-0.28 & 0.24 & 0.01 & 0.43 & -0.02 \\
\hline
\end{tabular}

\section{Conclusions}

1. According to the gradation of the correlation coefficients of the investigated indicated factors, the closest relationship is observed between the productivity and the number of rotors $x_{1}$. The increase in the number of rotors from 1 to 2 causes a productivity increase of 2 times. The following factors in the tightness of connection are the initial material size $x_{2}$, the growth of the initial material size by $1 \%$ causes a drop in productivity by $0.75 \%$; the strength of the material $x_{3}$, the increase in the strength of the initial material by $1 \%$ causes a 
decrease in productivity by $0.6 \%$; the number of revolutions of the disintegrator shaft $x_{4}$, the increase in the number of revolutions of the shaft by $1 \%$ causes an increase in productivity by $0.31 \%$.

2. According to the gradation of the correlation coefficients of the investigated indicated factors, the closest relationship is observed between the number of revolutions of the disintegrator shaft $x_{4}$ and power consumption. The increase in the number of revolutions of the disintegrator shaft in $1 \%$ causes a power consumption increase in $1.37 \%$. The following factors in the tightness of connection are the initial material size $x_{2}$, the growth of the initial material size by $1 \%$ causes an increase of power consumption by $0.7 \%$; the strength of the material $x_{3}$, the increase in the strength of the initial material by $1 \%$ causes an increase of power consumption by $0.24 \%$; the number of rotors $x_{1}$, increase in the number of rotors from 1 to 2 causes an increase of power consumption by $15 \%$.

3. Thus, it is obvious that an increase in the number of rotors leads to a significant increase in the disintegration productivity with a minimum increase in power consumption.

4. The given equations are the most representative and acceptable for disintegrators of the same size (or approximate ones), as the investigated laboratory stand. For disintegrators of other sizes, additional research is needed to specify the coefficients in the obtained equations.

\section{References}

1. Dyrda, V.I., Loginova, A.A. (2015). Nekotoryye problemy energosberezheniya pri razrushenii mineral'nogo syr'ya $\mathrm{V}$ udarno-tsentrobezhnykh drobilkakh. Geotekhnicheskaya mekhanika: Mezhvedomstvennyy sbornik nauchnykh trudov IGTM NAN Ukrainy [Geotechnical mechanics: Interdepartmental collection of scientific works IGTM NAS of Ukraine], 121, 121-125

2. Matsyuk, I.N., Shlyahov, E.M., Yehurnov O.I. (2018). Some aspects of synthesis of linkage of complex structures, Naukovyi Visnyk Natsionalnoho Hirnychoho Universytetu [Scientific Bulletin of National Mining University], 3, 57-63

3. Naduty, V.P., Ziborov, K.A, Loginova, A.O. (2017). Udarno-vidtsentrovyy dezintehrator. Patent No 116387, Ukraine

4. Naduty, V.P., Suharyev, V.V., Loginova, A.A. (2016). Effektivnost ispolzovaniya udarno-tsentrobezhnogo dezintegratora, realizuyushchego sdvigovyye deformatsii pri razrushenii gornoy massy. Geotekhnicheskaya mekhanika: Mezhvedomstvennyy sbornik nauchnykh trudov IGTM NAN Ukrainy [Geotechnical mechanics: Interdepartmental collection of scientific works IGTM NAS of Ukraine], 131, 26-32

5. Naduty, V.P., Loginova, A.O., Suharyev, V.V. (2017). Udarno-vidtsentrovyy dezintehrator. Patent No 119892, Ukraine

6. K. Carlberg, Regression analysis in Microsoft Excel (Dialectic-Williams, 2017) 